\title{
Effects of alternate moistube-irrigation on soil water infiltration
}

\author{
Lixia Shen ${ }^{1 *}$, Yumeng Zhang ${ }^{2}$, Mei Yang ${ }^{1}$, Ronghao Liu $^{1}$ \\ (1. College of Water Conservancy and Engineering, Taiyuan University of Technology, Taiyuan 030024, China; \\ 2. College of Urban and Environmental Science, Northwestern University, Xi'an 710127, China)
}

\begin{abstract}
Alternate moistube-irrigation is a new type of water-saving irrigation, and research on water infiltration with alternate moistube-irrigation is important for the design of irrigation schemes and helpful to understand and apply this technology. The effects of the pressure head $(1.0 \mathrm{~m}$ and $1.5 \mathrm{~m})$ and tube spacing $(10 \mathrm{~cm}, 20 \mathrm{~cm}$, and $30 \mathrm{~cm}$ between two moistubes respectively) on soil water infiltration in alternate moistube-irrigation were studied in laboratory experiments, and the cumulative infiltration, discharge of the moistube, and shape and water distribution of the cross-section of the wetting front were determined. The cumulative infiltration increased quickly and linearly with the infiltration time at 0-96 $\mathrm{h}\left(R^{2}>0.99\right)$, and changed smoothly at 96-192 h with a basically steady infiltration rate. The discharge of the moistube increased rapidly at the beginning of irrigation, then decreased before stabilizing. The cumulative infiltrations and discharges of moistube under the $1.5 \mathrm{~m}$ pressure head were more than those under the $1.0 \mathrm{~m}$ pressure head. The shape of the cross-section of the wetting front for a single moistube was similar to a concentric circle. With the increase of tube spacing, the interaction between water infiltrations of two moistubes decreased. The soil water distributions around two moistubes were similar to each other under the $1.0 \mathrm{~m}$ pressure head and large tube spacing. When the tube spacing was $20 \mathrm{~cm}$, the soil water distribution was more uniform around two moistubes.
\end{abstract}

Keywords: alternate irrigation, moistube-irrigation, soil water infiltration, water use efficiency, water-saving irrigation DOI: $10.25165 /$ j.ijabe.20201304.5297

Citation: Shen L X, Zhang Y M, Yang M, Liu R H. Effects of alternate moistube-irrigation on soil water infiltration. Int J Agric \& Biol Eng, 2020; 13(4): 151-158.

\section{Introduction}

The shortage of freshwater resources has become a bottleneck of-restricting agricultural development and global food security ${ }^{[1-4]}$. In order to alleviate the contradiction between the shortage of freshwater resources and rising world food demand, many countries are actively developing water-saving irrigation methods ${ }^{[5-7]}$. Moistube-irrigation, also called semi-permeable membrane irrigation, is a new type of water-saving irrigation technology that has arisen in recent years in China ${ }^{[8]}$. Moistube-irrigation takes advantage of the special properties of semi-permeable membranes to provide timely and adequate moisture to crop root zones in a continuous flow mode so that soil is always kept moist ${ }^{[9-11]}$. As a result of the implementation of underground continuous irrigation by means of micro and slow release, deep seepage and surface evaporation are effectively controlled, resulting in saving of irrigation water. In addition, the system only needs a low-water-pressure head and negative pressure-potential of soil water to operate, thereby also saving energy. At present, Moistube-irrigation is gradually being promoted and applied to production in China ${ }^{[12-15]}$. The research on moistube-irrigation now mainly includes two aspects: soil box simulation test and plant cultivation test. The soil box simulation

Received date: 2019-07-18 Accepted date: 2020-05-13

Biographies: Yumeng Zhang, Master candidate, research interests: water-saving irrigation, Email: 491025435@qq.com; Mei Yang, PhD, Associate Professor, research interests: water-saving irrigation, Email: yangmei@ tyut.edu.cn; Ronghao Liu, PhD, Associate Professor, research interests: water-saving irrigation, Email: liuronghao@tyut.edu.cn.

*Corresponding author: Lixia Shen, PhD, Professor, research interests: water-saving irrigation. College of Water Resource Science and Engineering, Taiyuan University of Technology, Taiyuan 030024, China. Tel: +8613623608332, Email: shenlixia@tyut.edu.cn. test mainly focuses on the effects of pressure head, soil texture and bulk density on the characteristics of the wetting body front, the outflow and anticlogging performance of the tube $\mathrm{e}^{[10,11]}$. The plant cultivation test mainly focuses on the effects of pressure head, buried depth and spacing of tubes on crop growth and yield ${ }^{[13-15]}$. However, most researches currently focus on conventional continuous irrigation, and researches on other irrigation modes are relatively rare.

As early as the 1970s, alternate row irrigation or alternate furrow irrigation was attempted for some crops. Since the 1990s, some scholars have thoroughly studied the principle of plant root signals under water stress, providing a theoretical basis for alternative irrigation ${ }^{[16-19]}$. Controlled alternate partial root-zone irrigation technology is a water-saving irrigation technology that can not only satisfy crop water demand but also control ineffective transpiration. It can reduce plant transpiration and ineffective evaporation of soil moisture by irrigating part of the root zone alternately during some or all growth stages of crops, while other root zones are under artificial water stress, so as to save water and improve water use efficiency. At present, many studies on alternate furrow irrigation ${ }^{[20-24]}$ and alternate drip irrigation ${ }^{[25-29]}$ have been carried out on many crops. Wei et al. ${ }^{[30]}$ reported that, compared with conventional moistube-irrigation, the alternate moistube-irrigation with a watering interval of $2 \mathrm{~d}$ significantly improved tomato water use efficiency without significantly reducing the fruit yield. The reason was that the alternate moistube-irrigation stimulated a compensating effect on tomato root absorbency, and enhanced the ability to absorb soil water. However, research on the combination of moistube-irrigation and alternative irrigation is rare, and research on the infiltration and migration of soil water under alternative moistube-irrigation is still scarce.

The objective of this study was to determine the effects of the 
pressure head and tube spacing on cumulative infiltration, discharge of the moistube, and the shape and water distribution of the cross-section of the wetting front in alternate moistube-irrigation through laboratory experiments.

\section{Materials and methods}

\subsection{Experimental details}

The experiments were carried out in the College of Water Conservancy and Engineering, Taiyuan University of Technology, China from March to June in 2018. The equipment used in the laboratory experiment (presented in Figure 1) includes a Mariotte bottle, moistube pipe, water delivery pipe, soil box, and movable bracket. Two Mariotte bottles were used to maintain constant pressure head, and different pressure heads were produced by the Mariotte bottles placed on an adjustable height bracket. Two water delivery pipes of black polyethylene (PE) with inner diameters of $16 \mathrm{~mm}$ were connected to the Mariotte bottle and moistube pipe. Water supply was controlled by installed valves, and alternate moistube-irrigation was carried out by opening and closing the valve at different times. The water used in the experiment was filtered urban tap water. The moistube pipe was $1 \mathrm{~m}$ long with an inner diameter of $16 \mathrm{~mm}$, and a wall thickness of $1 \mathrm{~mm}$. The moistube pipe was produced by Shenzhen Moistube Irrigation Co., Ltd. The soil box was made of transparent plexiglass and was $100 \mathrm{~cm} \times 40 \mathrm{~cm} \times 40 \mathrm{~cm}$ (length, width, and height). Holes with different spacing distances $(10 \mathrm{~cm}, 20 \mathrm{~cm}$, and $30 \mathrm{~cm}$ ) in both short side panels of the soil box were used to accommodate the moistube pipe, and the short side panels of the soil box were detachable. Samples of clay loam soil were evenly mixed and screened by a $2 \mathrm{~mm}$ sieve after drying and rolling. As determined by an MS 2000 laser particle size analyzer, the particle size ranges of $d \leq 0.002 \mathrm{~mm}, 0.002<d \leq 0.02 \mathrm{~mm}$, and $0.02<d \leq 2 \mathrm{~mm}$ were $23.30 \%, 40.58 \%$, and $36.12 \%$, respectively. The soil bulk density was set at $1.3 \mathrm{~g} / \mathrm{cm}^{3}$, and the initial soil water content was $1.38 \%$.

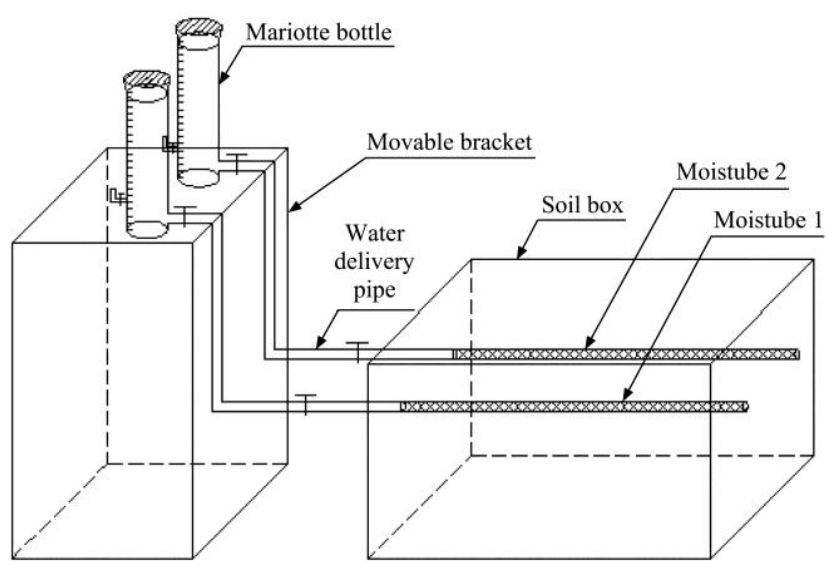

Figure 1 Experimental setup

\subsection{Treatments and measurements}

Treatments in the laboratory experiment consisted of the factorial combinations of (i) two pressure heads of $1 \mathrm{~m}$ and $1.5 \mathrm{~m}$ (H1 and $\mathrm{H} 2$ ), and (ii) three tube spacings of $10 \mathrm{~cm}, 20 \mathrm{~cm}$, and $30 \mathrm{~cm}$ (S1, S2, and S3). According to the required bulk density, a certain amount of soil sample was loaded into the soil box and, when the soil thickness reached $30 \mathrm{~cm}$, two moistube pipes were laid horizontally with different tube spacings, and then another $10 \mathrm{~cm}$ of soil was loaded. Three replicates were adopted in all experiments. The water levels of two Mariotte bottles were recorded before the start of the test, and then the valve of moistube 1 (M1) was opened to supply water. After $4 \mathrm{~d}$, the valve of M1 was closed, and then the valve of moistube 2 (M2) was opened to supply water for another $4 \mathrm{~d}$. The total testing times for each of the treatments of H1S1, H1S2, H1S3, H2S1, H2S2, and H2S3 were $8 \mathrm{~d}$. The total testing time for each of the treatments of H1S2-2 and H2S2-2 was $16 \mathrm{~d}$, with the valves of M1 and M2 opened and closed a second time for another $4 \mathrm{~d}$. For the first $12 \mathrm{~h}$ of water supply, the water level of the Mariotte bottle was recorded every $2 \mathrm{~h}$, and then the water level was recorded every $12 \mathrm{~h}$. Cumulative infiltration and the discharge of the moistube were calculated according to the time period. The wetting front position on both sides of the soil box was drawn, and the shape of the cross section of the wetting front was depicted with AutoCAD. Soil water contents in the cross section of the wetting front were measured by a drying method at the end of the test. The short side panel of the soil box near the end of the moistube pipe was removed, and soil samples were taken from the soil cross section to determine the soil moisture content. Soil sampling points were $5 \mathrm{~cm}, 10 \mathrm{~cm}, 15 \mathrm{~cm}, 20 \mathrm{~cm}, 25 \mathrm{~cm}, 30 \mathrm{~cm}$, and $35 \mathrm{~cm}$ longitudinally from the surface of the soil cross section, and $5 \mathrm{~cm}$, $10 \mathrm{~cm}, 15 \mathrm{~cm}, 20 \mathrm{~cm}, 25 \mathrm{~cm}, 30 \mathrm{~cm}$, and $35 \mathrm{~cm}$ horizontally from the left side (near M1) of the soil cross section.

\subsection{Data analysis}

Analysis of variance was performed to determine the effect of alternate moistube-irrigation on cumulative infiltration and discharge of the moistube using Tukey's Honest Significant Difference (HSD) test. Statistical analysis was performed using IBM SPSS Statistics version 20.0 (IBM Corporation, Somers, New York).

\section{Results and discussion}

\subsection{Cumulative infiltration}

Cumulative infiltration under different pressure heads and tube spacing in alternate moistube-irrigation is shown in Figure 2. The cumulative infiltration of M1 and M2 increased linearly with the infiltration time at $0-96 \mathrm{~h}\left(R^{2}>0.99\right)$. Pressure head was an important factor affecting water infiltration: the greater the pressure head, the greater the cumulative infiltration. The cumulative infiltration of M1 and M2 under the $1.5 \mathrm{~m}$ pressure head was significantly more than that under the $1.0 \mathrm{~m}$ pressure head $(p<0.05)$.

For the treatments of H1S1, H2S1, and H2S2, the cumulative infiltration of M1 was significantly more than that of M2 $(p<0.05)$, while for the treatments of H1S2, H1S3, and H2S3, the cumulative infiltration of M1 was nearly equal to that of M2. When the tube spacing was S1, the soil wetting front of M1 had moved to the vicinity of M2 before M2 began to supply water, thus the cumulative infiltration of M2 was low due to high soil water content. When the tube spacing was S2, the soil wetting front of M1 migrated a small distance under the $1.0 \mathrm{~m}$ pressure head, which had little effect on M2, but under the $1.5 \mathrm{~m}$ pressure head, the soil wetting front of M1 migrated a large distance, thereby affecting the infiltration of M2. When the tube spacing was S3, the infiltrations of M1 and M2 had little effect on each other.

The cumulative infiltration of M1 and M2 increased with the infiltration time quickly at 0-96 h, and changed smoothly at 96$192 \mathrm{~h}$ with a basically steady infiltration rate. At 0-192 h, the relationship between the cumulative infiltration of M1 and M2 and infiltration time can be expressed by a polynomial equation $\left(R^{2}>0.99\right)$. 

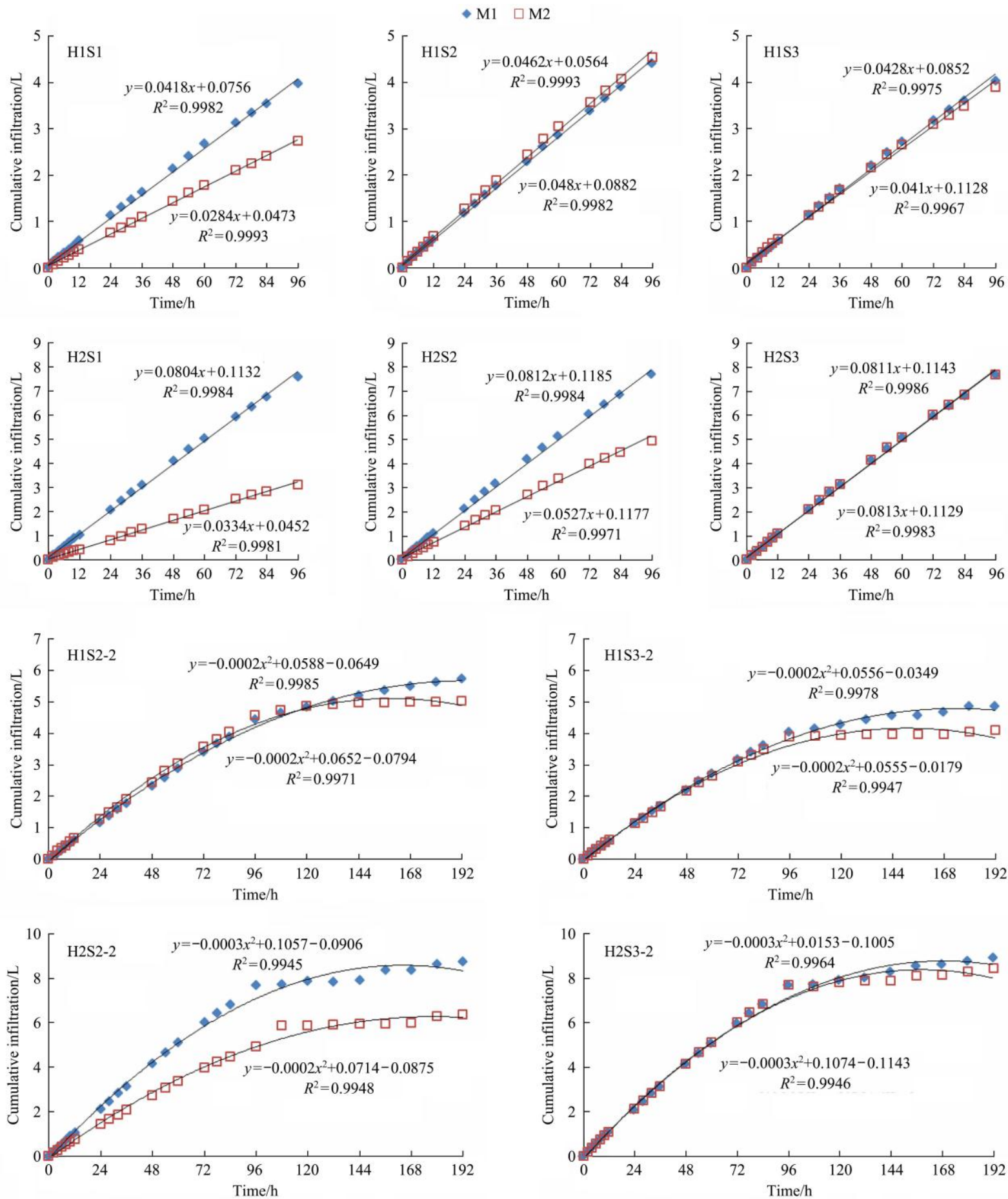

Note: $\mathrm{H} 1$ and $\mathrm{H} 2$ represent pressure heads of $1.0 \mathrm{~m}$ and $1.5 \mathrm{~m} ; \mathrm{S} 1, \mathrm{~S} 2$, and $\mathrm{S} 3$ represent tube spacing of $10 \mathrm{~cm}, 20 \mathrm{~cm}$, and $30 \mathrm{~cm}$; M1 and M2 represent moistube 1 and 2; $y$ represents the cumulative infiltration and $\mathrm{x}$ represent the infiltration time.

Figure 2 Cumulative infiltration in alternate moistube-irrigation

\subsection{Discharge of the moistube}

The discharge of the moistube under different pressure heads and tube spacings in alternate moistube-irrigation is shown in Figure 3. The discharges of M1 and M2 for the treatments of $\mathrm{H} 1 \mathrm{~S} 1, \mathrm{H} 1 \mathrm{~S} 2, \mathrm{H} 1 \mathrm{~S} 3, \mathrm{H} 2 \mathrm{~S} 1, \mathrm{H} 2 \mathrm{~S} 2$, and $\mathrm{H} 2 \mathrm{~S} 3$ increased rapidly at $0-6 \mathrm{~h}$ or $0-8 \mathrm{~h}$, then decreased at $6-24 \mathrm{~h}$ or $8-24 \mathrm{~h}$, and changed smoothly at 24-96 h. The discharges of M1 and M2 under the $1.5 \mathrm{~m}$ pressure head were significantly more than those under the $1.0 \mathrm{~m}$ pressure head $(p<0.05)$.

For the treatments of H1S1, H2S1, and H2S2, the discharges of M1 were significantly more than those of M2 $(p<0.05)$, while for the treatments of H1S2, H1S3, and H2S3, the discharges of M1 were nearly equal to those of M2. When the tube spacing was S1 or S2, the difference between the discharges of M1 and M2 under the $1.5 \mathrm{~m}$ pressure head was larger than that under the $1.0 \mathrm{~m}$ pressure head. For the treatments of H1S2-2, H1S3-2, H2S2-2, and $\mathrm{H} 2 \mathrm{~S} 3-2$, the discharges of the moistube at 96-192 $\mathrm{h}$ were lower than those at 24-96 h, as the soil was wetter when the moistube began to supply water the second time than before irrigation.

The discharge of the moistube increased rapidly at the beginning of irrigation, then decreased and remained at a stable level as time elapsed. There was an induction period that was probably within $24 \mathrm{~h}$ from the start of moistube-irrigation, and discharge of the moistube remained stable after $24 \mathrm{~h}$ of irrigation. Niu et al. ${ }^{[31]}$ reported that the moistube had a weak and short duration of self-regulated flow with changes in soil moisture 
content at approximately $44 \mathrm{~h}$, and the flow increased quickly and then decreased to a steady state after $48 \mathrm{~h}$ of irrigation. The difference of the time needed for the stable discharge of the moistube may be related to the pressure head, soil bulk density, soil texture, soil initial water content, and/or different test conditions.
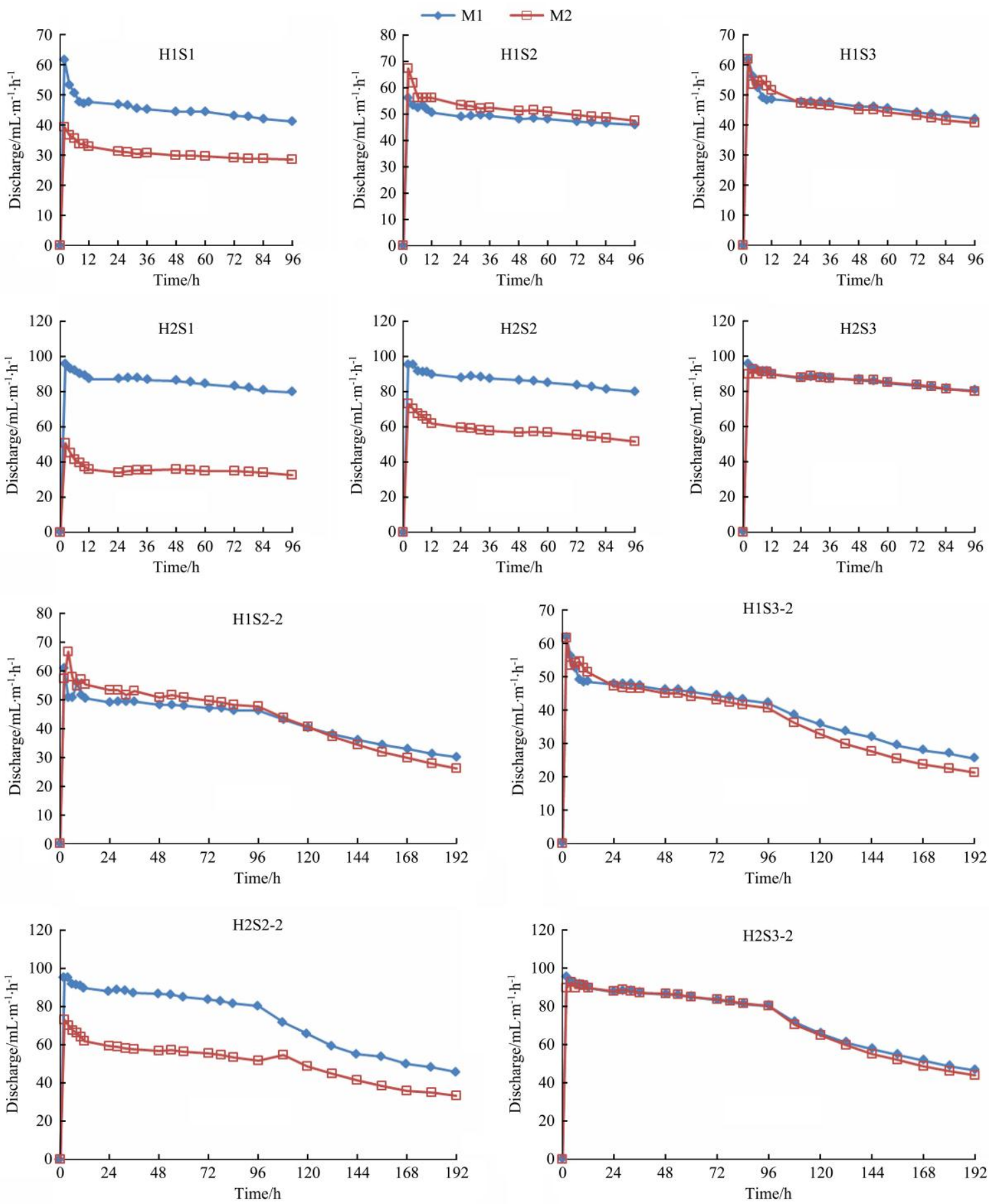

Figure 3 Discharge of the moistube in alternate moistube-irrigation

\subsection{Shape of the cross-section of the wetting front}

The shape of the cross-section of the wetting front under different pressure heads and tube spacings in alternate moistube-irrigation is shown in Figure 4. The shape of the cross-section of the wetting front for a single moistube was similar to a concentric circle, and the area of the cross-section of the wetting front under the $1.5 \mathrm{~m}$ pressure head was larger than that under the $1.0 \mathrm{~m}$ pressure head. The wetting fronts of M1 and M2 were superposed when the tube spacing was S1, were a little superposed when the tube spacing was S2, and did not affect each other when the tube spacing was S3. Zhang et al. ${ }^{[32]}$ reported that wetted soil with moistube-irrigation looked like a cylindrical object, with the pipe at the axle center of its cross section, which for clay loam soil was approximately cylindrical, and for sandy soil was of obpyriform shape. The same result for clay loam soil was obtained in this experiment.

\subsection{Water distribution in the cross-section of the wetting front}

Figure 5 shows the water distribution in the cross-section of the wetting front in alternate moistube-irrigation at the end of the test. For the treatments of H1S1, H1S2, H2S1, and H2S2 in which the test ended in $8 \mathrm{~d}$, the soil around M2 had higher water content than that far away from M2 as the water supply from M2 had just finished, and the water migrated longer distances under the $1.5 \mathrm{~m}$ pressure head than under the $1.0 \mathrm{~m}$ pressure head. 

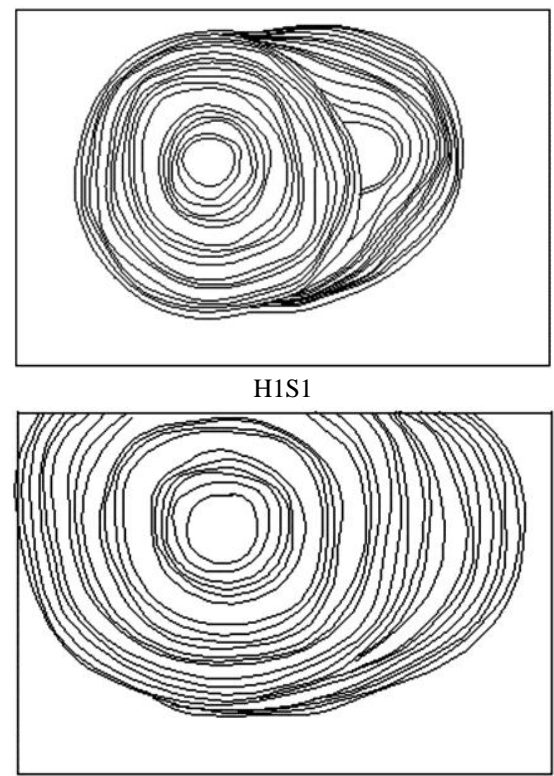

H2S1
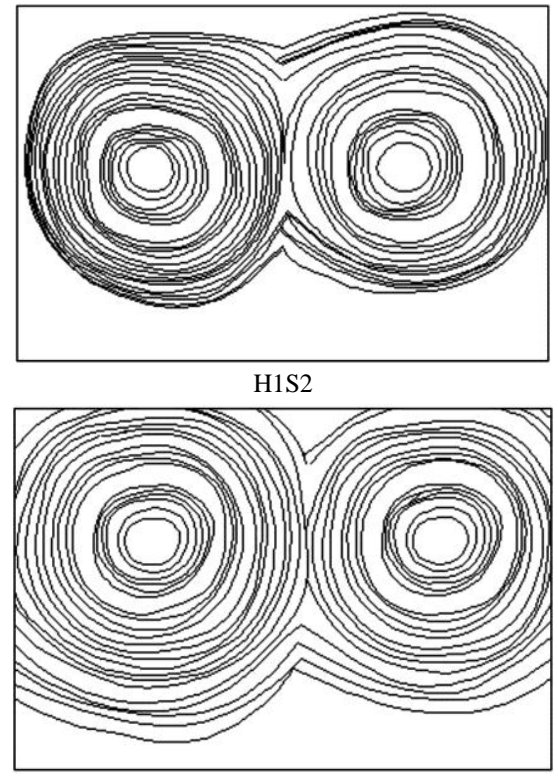

$\mathrm{H} 2 \mathrm{~S} 2$

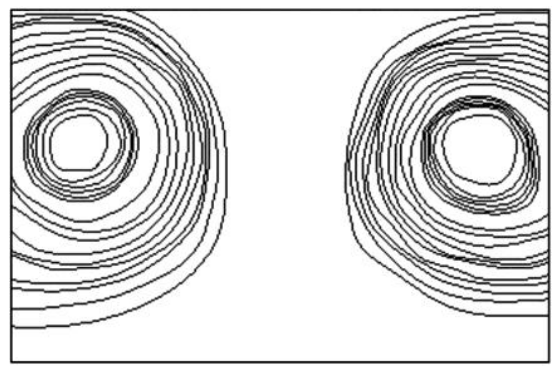

H1S3

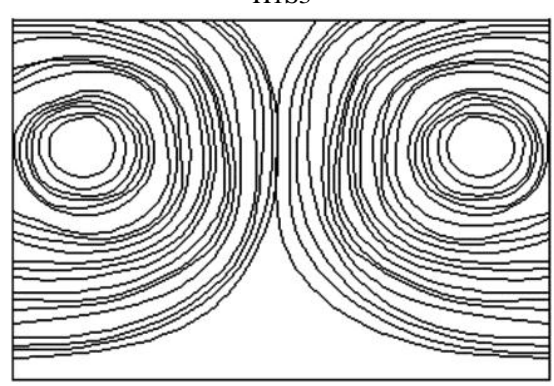

$\mathrm{H} 2 \mathrm{~S} 3$

Figure 4 Shape of the cross-section of wetting front in alternate moistube-irrigation
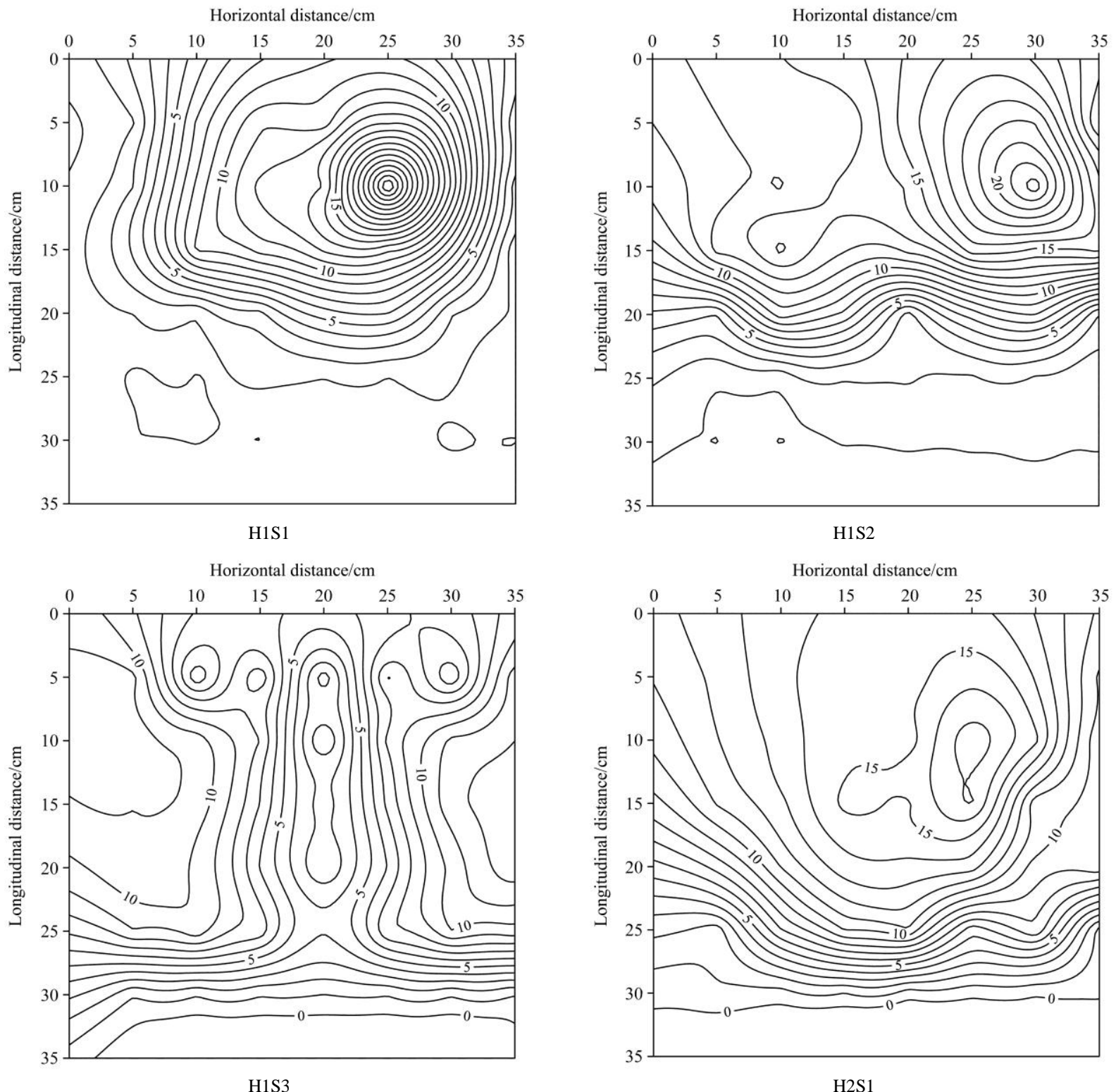

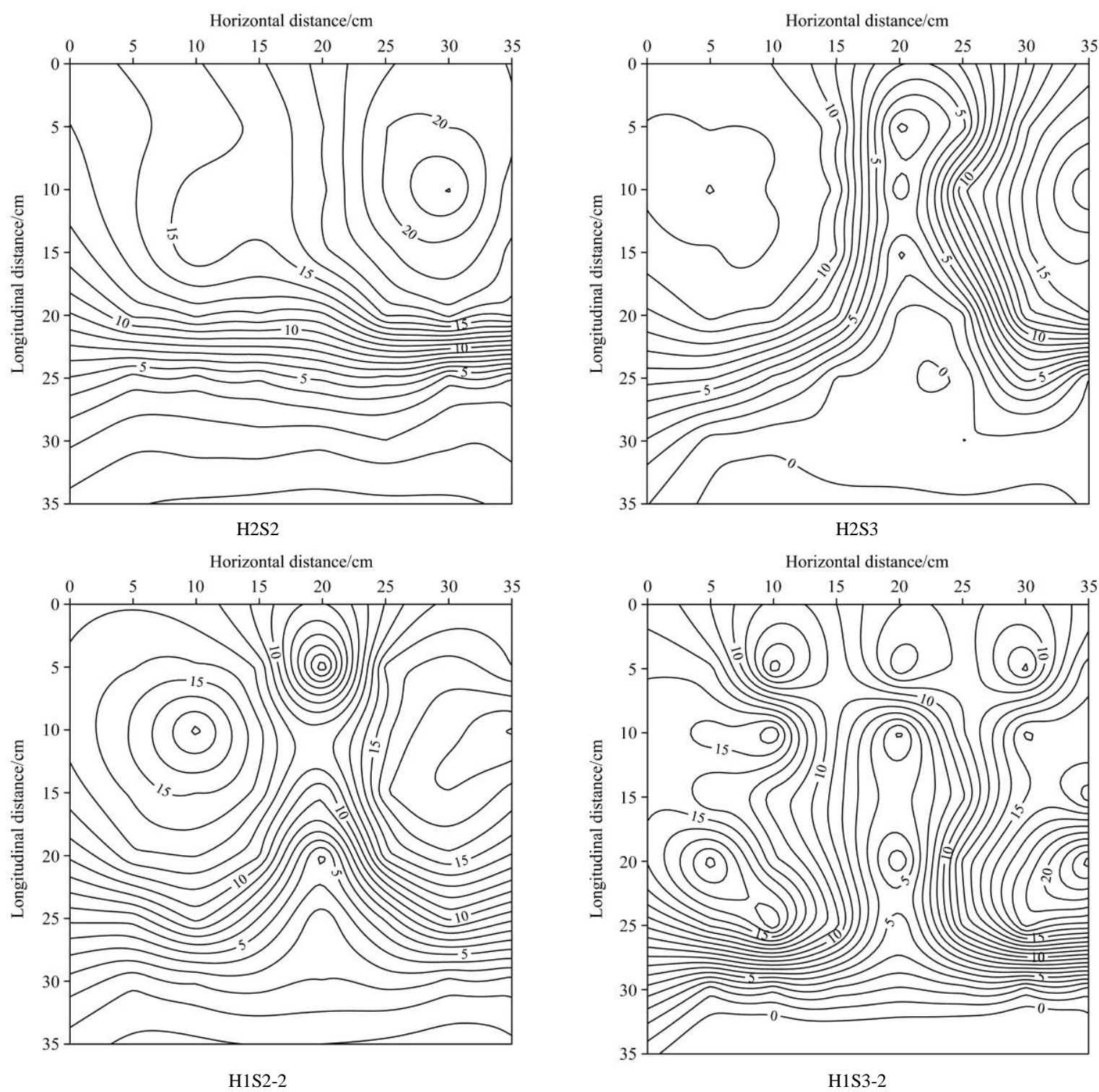

H1S3-2

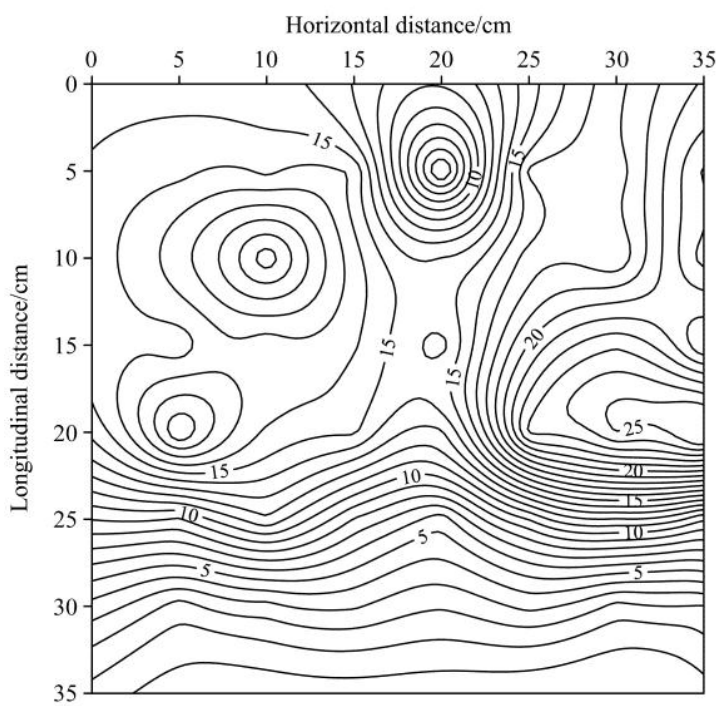

$\mathrm{H} 2 \mathrm{~S} 2-2$

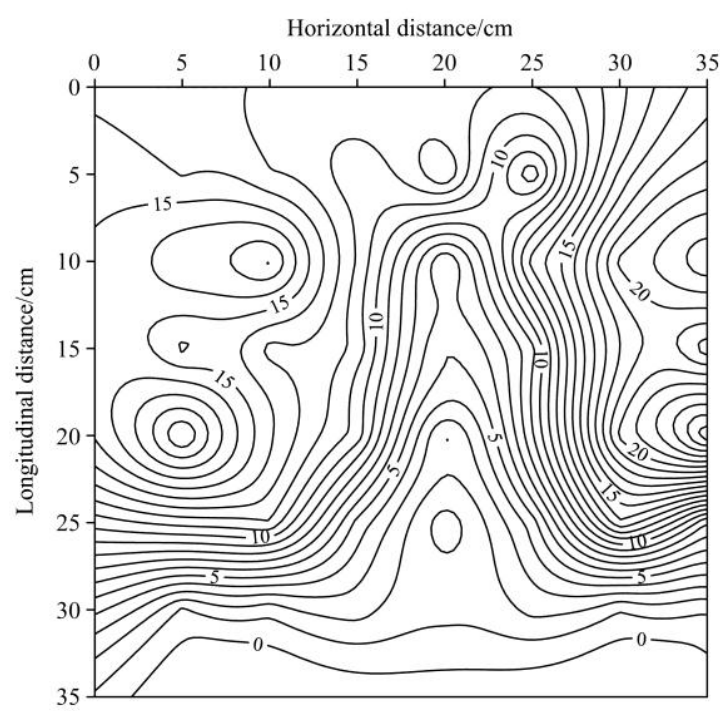

$\mathrm{H} 2 \mathrm{~S} 3-2$

Figure 5 Water distribution in the cross-section of the wetting front in alternate moistube-irrigation at the end of the test

For the treatment of H1S3, the soil water distributions around M1 and M2 were similar to each other, as water supplies from M1 and M2 did not affect each other under the pressure head of $1.0 \mathrm{~m}$ and the large tube spacing of S3. For the treatment of H2S3, the range of water migration was larger than that for the treatment of
H1S3 as water migrated over longer distances under the $1.5 \mathrm{~m}$ pressure head.

When the test ended in $16 \mathrm{~d}$, the soil near M1 had higher water content for the treatments of H1S2-2 and H2S2-2 than that for the treatments of H1S2 and H2S2, and the soil water distribution was 
more uniform around M1 and M2. For the treatment of H1S3-2, as for the treatment of H1S3, the soil water distributions around M1 and M2 were similar to each other, and the difference between H1S3-2 and H1S3 was that the soil had higher water content for H1S3-2. For the treatment of H2S3-2, the soil near M1 had higher water content than that for $\mathrm{H} 2 \mathrm{~S} 3$, and the water distribution range for $\mathrm{H} 2 \mathrm{~S} 3-2$ was larger than that for $\mathrm{H} 2 \mathrm{~S} 3$.

\section{Conclusions}

The effects of the pressure head and tube spacing on soil water infiltration in alternate moistube-irrigation were studied in laboratory experiments, and the cumulative infiltration, discharge of the moistube, and shape and water distribution of the cross-section of the wetting front were determined. With the infiltration time from 0 to $96 \mathrm{~h}$, the cumulative infiltration volume of M1 and M2 increased rapidly and linearly $\left(R^{2}>0.99\right)$, while from $96 \mathrm{~h}$ to $192 \mathrm{~h}$, it changed smoothly and the infiltration rate was basically stable. Pressure head was an important factor affecting water infiltration, and the greater the pressure head, the greater the cumulative infiltration. The cumulative infiltrations of $\mathrm{M} 1$ and M2 under the $1.5 \mathrm{~m}$ pressure head were more than those under the $1.0 \mathrm{~m}$ pressure head. With increased tube spacing, the interaction between water infiltration of M1 and M2 decreased. The discharges of M1 and M2 under the $1.5 \mathrm{~m}$ pressure head were more than those under the $1.0 \mathrm{~m}$ pressure head. At the beginning of moistube-irrigation, the discharge of water increased rapidly, then decreased and remained at a stable level over time. The water induction period might exist within $24 \mathrm{~h}$ after the start of irrigation, and the water flow remained stable after $24 \mathrm{~h}$ of irrigation. The cross-sectional shape of the wetting front of a single moistube resembled a concentric circle. The cross-sectional area of the wetting front under the $1.5 \mathrm{~m}$ pressure head is greater than that under the $1.0 \mathrm{~m}$ pressure head. With increased tube spacing, the interaction of the wetting bodies between M1 and M2 decreased. The soil water distributions around M1 and M2 were similar to each other under the $1.0 \mathrm{~m}$ pressure head and large tube spacing of S3. When the tube spacing was S2, the soil near M1 had higher water content when the test ended in $16 \mathrm{~d}$ compared to when the test ended in $8 \mathrm{~d}$, furthermore, soil water distribution was more uniform around M1 and M2.

The laboratory experiments differed in a few ways from what could be expected with actual field conditions, and the effect of alternate moistube-irrigation on plant growth should be investigated in the field.

\section{Acknowledgements}

This work was supported by the National Natural Science Foundation for Young Scientists of China (51809189), the Natural Science Foundation (201701D121109, 201801D121266), and the Key Research and Development Plan (201703D211020-2) of Shanxi Province, China.

\section{[References]}

[1] Panigrahi B, Sharma S D, Behera B P. Irrigation water requirement models of some major crops. Water Resources Management, 1992; 6(1): 69-77.

[2] Sauer T, Havlík P, Schneider U A. Agriculture and resource availability in a changing world: the role of irrigation. Water Resources Research, 2010; 46(6): 666-669.

[3] Stigter T Y, Varanda M, Bento S, Nunes J P, Hugman R. Combined assessment of climate change and socio-economic development as drivers of freshwater availability in the South of Portugal. Water Resources Management, 2017; 3(2): 609-628.

[4] Zilov E A. Water resources and the sustainable development of humankind: International cooperation in the rational use of freshwater-lake resources: Conclusions from materials of foreign studies. Water Resources, 2013; 40(1): 84-95.

[5] Peterson J M, Ding Y. Economic adjustments to groundwater depletion in the high plains: do water-saving irrigation systems save water? American Journal of Agricultural Economics, 2005; 87(1): 147-159.

[6] Fang Q X, Ma L, Green T R, Yu Q, Wang T D, Ahuja L R. Water resources and water use efficiency in the North China Plain. Current status and agronomic management options. Agricultural Water Management, 2010; 97(8): 1102-1116.

[7] Mostafa H, Fujimoto N. Water saving scenarios for effective irrigation management in Egyptian rice cultivation. Ecological Engineering, 2014; 70(5): 11-15.

[8] Yang Q L. Irrigation method with semi permeable membrane, irrigation container and irrigation system made of semi permeable membrane and their application. European Patent Application EP2153714 A1, 17 February, 2010.

[9] Tang Y, Du L, Yang W R, Xu L G. Experimental study on soil moisture change characteristics under fruit trees moistube-irrigation condition. Water Saving Irrigation, 2014; 4: 27-34. (in Chinese)

[10] Fan Y W, Huang N, Gong J G, Shao X X, Zhang J, Zhao T. A simplified infiltration model for predicting cumulative infiltration during vertical line source irrigation. Water, 2018; 10(1): 89. doi: 10.3390/w10010089.

[11] Fan Y W, Huang N, Zhang J, Zhao T. Simulation of soil wetting pattern of vertical moistube-irrigation. Water, 2018; 10(5): 601. doi: 10.3390/w10050601.

[12] Zhang L S, Dou C Y, Li G Y, Li C L. Application of self-suction micro-irrigation to baby cabbage planting in greenhouses. Rural Water Conservancy and Hydropower in China, 2013; 4: 53-55. (in Chinese)

[13] Xue W L, Niu W Q, Zhang Z Z. Effects of the tomato growth and water use efficiency in sunlight greenhouse by moistube-irrigation. Agricultural Research in Arid Areas, 2013; 31(6): 61-66. (in Chinese)

[14] Tian D L, Zheng H X, Li X T. Study on moistube irrigation for sunflower growth. Water Saving Irrigation, 2016; 9: 94-97. (in Chinese)

[15] Zhang M Z, Wang J W, Li Y, Wang J W, Qiu X Q, Li Y. Effects of moistube irrigation on winter wheat's yield and irrigation water use efficiency. Journal of Irrigation \& Drainage, 2018; 37(1): 8-15. (in Chinese)

[16] Sadras V O. Does partial root-zone drying improve irrigation water productivity in the field? A meta-analysis. Irrigation Science, 2009; 27(3) 183-190.

[17] Vera J, Abrisqueta I, Abrisqueta J M, Ruiz-sánchez M C. Effect of deficit irrigation on early-maturing peach tree performance. Irrigation Science, 2013; 31(4): 747-757.

[18] Davies W J, Zhang J. Root signals and the regulation of growth and development of plants in drying soil. Annu. Rev. Plant Physiol. Plant Mol. Biol., 1991; 42(1): 55-76.

[19] Abrisqueta I, Ayars J E. Effect of Alternative irrigation strategies on yield and quality of Fiesta raisin grapes grown in California. Water, 2018 10(5): 583. doi: 10.3390/w10050583.

[20] Panigrahi B, Panda, S N, Raghuwanshi N S. Potato yield and water-use-efficiency under furrow irrigation. Irrigation Science, 2001; 20(4): 155-163.

[21] Webber H A, Madramootoo C A, Bourgault M, Horst M G, Stulina G, Smith D L. Water use efficiency of common bean and green gram grown using alternate furrow and deficit irrigation. Agricultural Water Management, 2006; 86(3): 259-268.

[22] Slatni A, Zayani K, Zairi A, Yacoubi S, Salvador R, Playán E. Assessing alternate furrow strategies for potato at the Cherfech irrigation district of Tunisia. Biosystems Engineering, 2011; 108(2): 154-163.

[23] Sarker K K, Akanda M A R, Biswas S K, Roy D K, Khatun A, Goffar M A Field performance of alternate wetting and drying furrow irrigation on tomato crop growth, yield, water use efficiency, quality and profitability. Journal of Integrative Agriculture, 2016; 15(10): 2380-2392.

[24] Siyal A A, Mashori A S, Bristow K L, Van Genuchten M T. Alternate furrow irrigation can radically improve water productivity of okra. Agricultural Water Management, 2016; 173: 55-60.

[25] Kang S, Zhang L, Hu X, Li Z, Jerie P. An improved water use efficiency for hot pepper grown under controlled alternate drip irrigation on partial roots. Scientia Horticulturae (Amsterdam), 2001; 89(4): 257-267.

[26] Du T, Kang S, Zhang J, Li F, Yan B. Water use efficiency and fruit 
quality of table grape under alternate partial root-zone drip irrigation. Agricultural Water Management, 2008; 95(6): 659-668.

[27] Du T, Kang S, Zhang J, Li F. Water use and yield responses of cotton to alternate partial root-zone drip irrigation in the arid area of north-west China. Irrigation Science, 2008; 26(2): 147-159.

[28] Selim T, Berndtsson R, Persson M, Somaida M, El-Kiki M, Hamed Y, et al Influence of geometric design of alternate partial root-zone subsurface drip irrigation (APRSDI) with brackish water on soil moisture and salinity distribution. Agricultural Water Management, 2012; 103: 182-190.

[29] Yang Q, Zhang F, Li F, Liu X. Hydraulic conductivity and water-use efficiency of young pear tree under alternate drip irrigation. Agricultural
Water Management, 2013; 119(Complete): 80-88.

[30] Wei Z H, Chen G, Xu S J, Du T S. Responses of tomato water consumption and yield to moistube irrigation under controlled alternate partial root-zone irrigation. Journal of Irrigation and Drainage, 2014; 33(4): 139-143. (in Chinese)

[31] Niu W Q, Zhang M Z, Xu J, Zou X Y, Zhang R C, Li Y. Prediction Methods and Characteristics of Flow for Moistube. Transactions of the CSAM, 2017; 48(6): 217-224. (in Chinese)

[32] Zhang J, Niu W Q, Zhang L L, Shi L Y. Experimental study on characters of wetted soil in moistube irrigation. Science of Soil and Water Conservation, 2012; 10(6): 32-38. (in Chinese) 